\title{
Referência Completa
}

Tipo da Referéncia Journal Article

Repositorio sid.inpe.br/irise1905/2005/07.28.03.04

Metadados sid.inpe.br/iris@1905/2005/07.28.03.04.48

Site mtc-m05.sid.inpe.br

Rótulo 2261

ISSN 0102-261X

Chave Secundária INPE-2432

Chave de Citaçăo AbduSobrNaka: 1985 : LoLaSc

Autor 1 Abdu, Mangalahyil Ali

2 Sobral, Jose Humberto Andrade

3 Nakamura, Y

Grupo 1 DAE-INPE $\rightarrow$ BR

Titulo on the low latitude scanning photometer signatures of the equatorial ionosphere plasma bubbles

Revista Revista Brasileira de Geofísica

Ano 1985

Volume 3

Número :

Palavas-Chave AERONOMIA.

Páginas 33-39

Tipo Secundário PRE PN

Divilgação PORTALCAPES; SCIELO.

Area CEA

Projeto IONO

Utitima Atualizaçåo dos Metadados 2014:09.29.15.19.50 administrator (D 1985)

Estágio do Documento concluido

e-Mail (login) marciana

Grupo de Usuários adninistrator

Visibilidade shown

Transferivel 1

Tipo do Conteudo External Contribution

Politica de Arquivamento allowpublisher allowfinaldraft

Unidade Imediatamente Superior 8JMKD3MGPCW / 3ETL868

Conteúdo da Pasta source nąo têm arquivos

Conteúdo da Pasta agreement nåo têm arquivos

Histórico 2014-09-29 15:19:50 :: administrator $\rightarrow$ marciana :: 1985

Campos vazios abstract affiliation alternatejoumal archivist callnumber copyholder copyright creatorhistory descriptionlevel documentstage doi e-mailaddress electronicmailaddress format isbn language lineage mark mirrorrepository month nextedition notes numberoffiles parameterlist parentrepositories previousedition 


\begin{tabular}{|c|c|c|c|}
\hline $\begin{array}{l}\text { 1. Publication Nọ } \\
\text { INPE-2432-PRE/136 }\end{array}$ & $\begin{array}{l}\text { 2. Version } \\
4 t h^{*}\end{array}$ & $\begin{array}{l}\text { 3. Date } \\
\text { June, } 1982\end{array}$ & \multirow{2}{*}{$\begin{array}{l}\text { 5. Distribution } \\
\square \text { Internal } 囚 \text { External } \\
\square \text { Restricted }\end{array}$} \\
\hline $\begin{array}{l}\text { 4. Origin } \\
\text { DGA/DIO } \\
\end{array}$ & $\begin{array}{l}\text { ogram } \\
\text { NOSFERA }\end{array}$ & & \\
\hline $\begin{array}{l}\text { 6. Key words - selec } \\
\text { PLASMA BUBBLE } \\
\text { AIRGLOW VALLEY } \\
\text { MERIDIONAL SCAN }\end{array}$ & by the aut & & \\
\hline
\end{tabular}

7. U.D.C.: $523.4-853$

\begin{tabular}{ll|ll} 
8. Title & INPE-2432-PRE/136 & 10. No of pages:
\end{tabular}

\section{ON THE LOW LATITUDE SCANNING PHOTOMETER SIGNATURES OF EQUATORIAL IONOSPHERE PLASMA BUBBLES}

\section{Authorship $M . A . A b d u$ \\ J.H.A. Sobral \\ Y. Nakamura}

Responsible author

11. Last page:

12. Revised by Bittencount J. A. Bittencourt

13. Authorized by<smiles>CC=CCC</smiles>

Marco Antonio Raupp General Director

\section{Abstract/Notes}

Meridional and east-west scan 63009 night airglow photometers are being extensively used at the low latitude station, Cachoeira Paulista $\left(23^{\circ} \mathrm{S}, 45^{\circ} \mathrm{W}\right.$, dip latitude 14\%), Brazil, for investigation of trans-equatorial ionospheric plasma bubbie dynamics. The zonal velocities of the flux tube aligned plasma bubbles can be determined, in a straightforward way, from the east-west displacement of the airglow intensity valleys observed by the east-west scan photometer. On the other hand the determination of the other velocity component of the plasma bubble motion (namely, vertical motion in the equatorial plane) has to be based on the meridional propagation of the airglow valleys observed by the meridional scan photometer. Such determinations of the bubbles' vertical rise velocity should, however, involve considerations on different bubble parameters such as, for example, the phase of the bubble event (whether growth, mature or decay phase), the limited east-west extension, and the often observed westward tilt of the bubble. In this brief report we have considered in some detail, possible influences of these different factors on the interpretation of low latitude scanning photometer data to infer trans-equatorial plasma bubble dynamics.

15. Remarks This work was partially supported by the "FNDCT" under contract FINEP-537/CT. This work is being submitted to Revista Brasileira de Geofísica.

*Revised work in August, 1985. 
ON THE LOW LATITUDE SCANNING PHOTOMETER SIGNATURES

OF EQUATORIAL IONOSPHERE PLASMA BUBBLES

M. A. ABDU, J. H. A. SOBRAL, AND Y. NAKAMURA

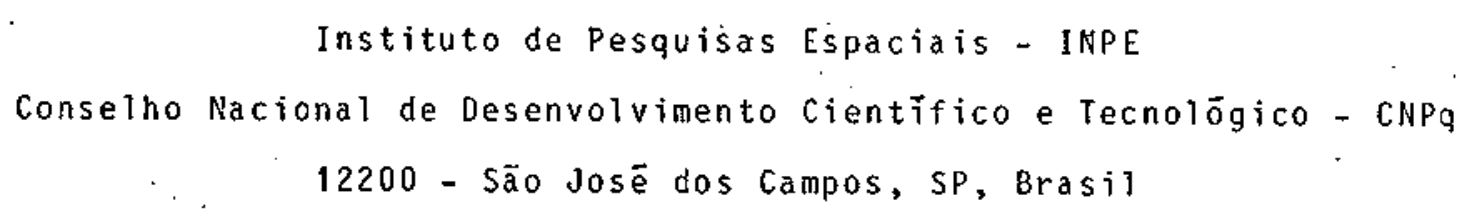


Meriojonal and east-west. scan $6300 \AA$ night airglow photometers are being extensively used at the low latitude station, Cachoeira Pautista $\left(23^{\circ} \mathrm{S} 45^{\circ} \mathrm{W}\right.$, dip latitude $\left.14^{\circ}\right)$, Brazil, for investigation of trans-equatorial ionospheric-plasma bubble dynamics. The zanal velocities of the flux tube aligned plasma bubbles can be determined, in a straightforward way, from the east-west displacement of the airglow intensity valleys observed by the east-west scan photometer. On the other hand the determination of the other velocity component of the plasma bubble motion (namely, vertical motion in the equatorial plane) has to be based on the meridional propagation of the airglow valleys observed by the meridional scan photometer. Such determinations of the bubbles' vertical rise velocity should, however, involve considerations on different bubble parameters such as, for exemple, the phase of the bubble event (whether. growth, mature or decay phase), the limited east-west extension, and the often observed westward tilt of the bubble. In this brief report we have considered in some detail, possible influences of these different factors on the interpretation of low latitude scanning photometer data to infer trans-equatorial plasma bubble dynamics.

E.

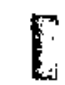<smiles>[3H][CH]</smiles>

$E$

!

I 
Medidas de varredura da luminescência do oxigēnio ato mico $(\lambda=6300 \AA)$ no periodo noturno, nos planos verticais Leste-0este e Norte-Sul (magnëticos), em Cachoeira'Paulista $\left(23^{\circ} \mathrm{S} 45^{\circ} \mathrm{W}\right.$, inclina cão $14^{\circ}$ ), Brasil, tem sido utilizadas em grande escala no estudo das chamadas bolhas ionosfëricas. Tais bolhas são zonas de deplecão de eletron e ions e extendèm-se por milhares de quilōmetros ao longo das linhas de força do campo magnético terrestre e transversalmente, por cerca de alqumas dezenas ou centenas de quilómetros. As velocida des dessas bolhas, no sentido leste-oeste, são facilmente determina das pelas medidas fotometricas. Por outro lado, velocidade vertical de propagação pode ser determinada pela sua projeção no plano verti cal meridional. Contudo a determinacão da componente vertical envol. ve consideracão de diversos parâmetros, tais como a fase da borha. (seja de crescimento, desenvolvida óu de decajmento), a limitada ex tensão leste-oeste e a frequentemente observada inclinaça da bolha. para oeste. Neste trabalho considerou-se possiveis influências des tes diferentes fatores na interpretacão de dados fotomëtricas de ba xa latitude, para inferir sobre a dinämica da bolha de plasma. 
Introduction

Bubble Signatures in the Meridional Scánning Data .......... 08 Duration of the Airglow valleys in the Meridional Scan Data... 10 Bubble Rise Velocity Determined From Meridional Velocity " of

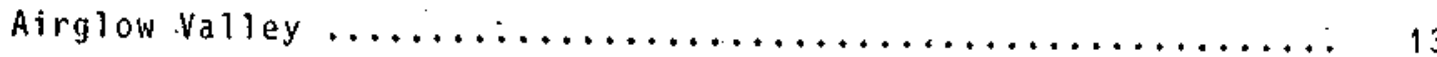

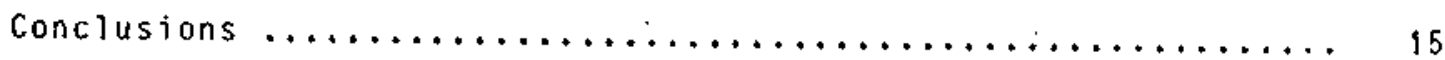

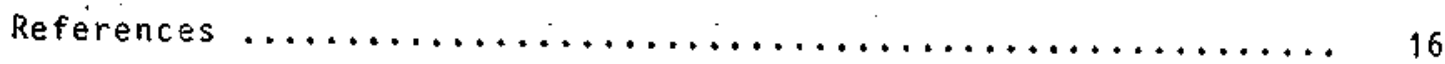


Regular measurements of ionosphere dynamics by northsouth and east-west 'scanning $6300 \AA$ airglow photometers are being carried out over the low latitude station Cachoeira Paulista $\left(23^{\circ} \mathrm{s}\right.$, $45^{\circ} \mathrm{W}$, dip lat. $\left.14^{\circ} \mathrm{S}\right)$, in Brazil. These measurements have detected propagating valleys in the airglow intensity profiles in the meridional as weil as in the east-west directions, occurring mostly from post-sunset to pre-midnight hours, and in the equinoctial and sumer months (Sobral at al., 1980a, 1980b, 1981). From comparison of the velocities of these propagating disturbances with those of the equatorial ionosphere plasma bubble, as measured from vhf radars and satellite instruments (Woodman \& La Hoz, 1976; McClure et al., 1977; Tsunoda, 1981) and from their occurrences in close association with those of the range type spread $F$ traces in the ionograms over Cachoeira Pauilista (Sobral et al., 19800), we have inferred that these airglow disturbances are, in fact, manifestations of the plasma bubble dynamics in the equatorial ionosphere. Different experimental studies have shown that the plasma bubbles and the associated irregularities occur highly field aligned along magnetic flux tubes (Aarons et al., 1980; Weber at a!., 1978; 1980; Mcclure et al., 1977; Dyson \& Benson, 1978; Tsunoda, 1980) extending several degrees into the low latitude ionosphere on either side of the magnetic equator, and drifts generally eastward in the corotating frame, and upward, with typical velocities of the order of $100 \mathrm{~m} \mathrm{~s}^{-1}$ and $200 \mathrm{~m} \mathrm{~s}^{-1}$, respectively, with large variations in these values (see also the other references cited above). Different results are consistent with the interpretation of the plasma bubble irregularities being 1: generated simultaneousiy within magnetic flux tubes, through the Rayleigh-Taylor mechanism under collisional regime, and also by Ex B drift instability mechanism, that operate at the steep electron density gradient region of the bottomside F-region during the post sunset hours, in the presence of naturally occurring ianization perturbations in the equatorial ionosphere (Haerendel, 1973; Anderson 
\& Haerendel, 1979; 0ssakow et al., 1979; Balsley et a1., 1972). As the field aligned plasma bubble and associated irregularities rise upward in the equatorial ionosphere, the low latitude extremities of the plasma bubble should propagate away from the equator such that the upper height limit of the bubble would also define the latitudinal extent of the bubble. Consistent with this picture, we have interpreted the poleward propagating airglow intensity valleys (or depletions) observed in our meridional scanning photometer data over Cachoeira Paulista as being produced by vertical rise of field aligned plasma depletions in the equatorial ionosphere. The velocities observed in the airglow data were compatible with those of the plasma bubble measured by vhf radars and sateltites when projected along the field lines. The east-west velocities of the valleys, on the other hand, were found to be directly comparable with the velocities of the bubble measured by the other techniques. Though our original interpretation of the meridional scanning data was found to agree with the gross behaviour of the plasma bubble, some detailed features of the meridional propagating disturbances do not seem to fit in with a simple picture of a vertically oriented plasma bubble rising vertically upward in the equatorial ionosphere. Detailed two dimensional shape of the plasma bubbles tranverse to the magnetic field has been presented recently by Tsunoda et al. (1982). These authors have shown, based on comparative study of east-west spatial relationship of ion density depletions measured in situ by the Atmospheric Explorer (AE-E) satellite and backscatter plumes measured by the ALTAIR radar, that plasma bubbles are vertically elongated depletions that extend upward from the bottomside of the F-layer in the form of wedges, having well-defined "head" and "neck" regions. They develop from bottomside altitude modulation region (Tsunoda and White, 1981) with the head region: tilted somewhat westward of the vertical, consistent with the westward drift (in the ambient plasma) of the plasma bubbles observed from $A E-C$ satellite measurement by Mcclure et al. (1977). The westward tilt of the elongated $6300 \&$ airglow depletions patches observed over low latitude by Weber et al. (1980), in fact, 
represents as they have interpreted, field line projection of such plasma bubble structures. It might be thought that the east-west drift of such tilted airglow patches could cause an apparent northsouth component in the velocities determined from meridional scanning photometer data. Another consequence of the westward tilt could be in the durations for which a given airglow valley is tracked in the meridional scanning photometer. The purpose of this note is to present a brief discussion about the influence of these and other factors on the interpretation of scanning photometer data, especialiy meridional scan data, with respect to the velocities and duration of the ajrglow valleys.

The westward tilt discussed above is highly variable. Satellite results of McClure et al. (1977) have indicated tilts of $10^{\circ}$ to $40^{\circ}$, whereas the radar plume structures presented by Tsunoda (1981) show tilts varying from zero up to about $45^{\circ}$. Further cross sectional views of the bubble tjlt have been presented by Tsunoda et. a). (1982). Considering that these tilts are measured in the equatorial plane, the displacements west of north in the airglow patches photographed by Weber et a1. (1978, 1980) are significantly smaller, from zero up to about $20^{\circ}$, which is understandable on the basis of the field line projection of the plasma bubble (see also Menditio and Baumgardner, 1982). Some possible causes of the westward tilt of the plasma bubble have been discussed by Tsunoda (1981) (see also Weber et a1,, 1980), and here we do not intend to discuss them further. We will consider here different degrees of tilts, and east-west and vertical velocities and dimension for the plasma bubble and examine their consequences on the observable durations of the airglow valleys in the scanning plane, and on the velocities of these valleys deduced from scanning data. 
Bubble Siqnatures in the Meridional Scannina Data

Fig.l presents some idealized cases of possible plasma bubble orientation in the equatorial plane (upper section). Straight lines are used in Figure 1 to represent the bubble axis. Ionization contours of the bubble, in cross section perpendicular to the magnetic field, as obtained from numerical simulation (ossakow et al., 1979), show the region of maximum depletion developing almost like a column with a certain degree of recovery to the ambient values that is abrupt at the top, and rather gradual in the lower part. This latter feature is not apparent in the two dimensional bubble shape produced by Tsunoda et al. (1982). For simplicity of the treatment to follow we have represented the bubble axis by straight lines al though they should present a certain degree of curvature towards ieft. The vertical dimension varies from $-100 \mathrm{~km}$ to $-400 \mathrm{~km}$ according to the plume maps presented by Tsunoda et al. (1982). Depending upon the development phase of the bubble, acertain portion of the straight lines up to a maximum of the order of $200 \mathrm{~km}$ from the upper end to downward could be considered to represent the position of the head region, or of maximum depletion, along the bubble axis. The east-west dimension of the plasma bubble could be taken to be of the order of $100 \mathrm{~km}$, from Tsunoda et al. (1982). The distances, along the $x$ and $y$ axes are in correct proportion.

Figure 1.

In part $\left(a_{1}\right)$ and $\left(b_{1}\right)$ of $F i g .1$ we have assumed that the tilt angle, $\theta_{t}$, (namely the angle that the bubble axis makes with vertical) is unchanging with time, which seems to be close to the observations of Tsunoda (1981) during the development phase of a bubble. In the part $\left(a_{1}\right)$ of the figure we have considered a probable extreme case of $\theta_{t}=45^{\circ}$ and the orientation of the bubble at its initial stage of development is shown by the line marked $t=0$, having a length of about $70 \mathrm{~km}$ and located at the reference longitude (say 
the longitude of the scanning measurement) indicated by the arrows. vertical rise velocity $\left(v_{y}\right)$ and eastward velocity $\left(v_{x}\right)$, both being taken for the sake of convenience as $100 \mathrm{~m} \mathrm{~s}^{-1}\left(v_{x} / v_{y}=1\right)$, are represented by the solid lines, and the bubble head for this case moves strictly vertically upward, namely remains overhead at the longitude of the bubble onset. The extensions of the solid lines by the broken 1 ines represent the case of $v_{x} / v_{y}=0.5$, namely, $v_{y}=200 \mathrm{~m} \mathrm{~s}^{-1}$, a typical case representative of an average situation as per published works (see for example Tsunoda; 1981). For this case we could observe that the bubble head moves westward of the stations as it rises up, which perhaps represents a rare situation.

Projection of the bubble axis (for the case $\left(a_{2}\right)$ ) along the magnetic field line, onto the low latitude f-layer at a height of $250 \mathrm{~km}$ is shown in part $\left(\mathrm{a}_{2}\right)$ of the figure in which the horizontal range of $600 \mathrm{~km}$ to $2200 \mathrm{~km}$ (from the equator) represents the photometer scanning range. Also marked is the latitude of the photometer location, $1400 \mathrm{~km}$ form the equator. The slant lines here represent the directions of orientation of the airglow depletion patches, drawn as field line projection, onto an altitude level of $250 \mathrm{~km}$, of the plasma bubble axis shown in the upper part of the figure. These slant lines, in practice, will not be straight, but would present a certain degree of curvature due to the horizontal stratification of the ionosphere as well as the westward curvature in the equatiorial plane mentioned before. The airglow intensity along the depeltion patches represented by these lines would depend upon the local electron density and height of the ionosphere. In general, the region of lowest intensity (corresponding to the maximum depletion of the bubble), that give rise to valleys in the north-south airglow profile, would be expected to be confined toward the poleward ends of these lines. The parts $\left(b_{1}\right)$ and $\left(b_{2}\right)$ of Figure 1 represent the bubble evolution for a different tilt angle, name $1 y, \theta_{t}=20^{\circ}$. The solid lines correspond to $v_{x} / v_{y}=1$, while the extensions of these by the broken lines represent the case of $v_{x} / v_{y}=0.5$, the separation of the lines being ilustrative 
of $v_{x}=100 \mathrm{~m}^{-1}$ as in the part $\left(a_{1}\right)$ of the figure. For this case the bubble head moves eastward of the station, since $v_{x} / v_{y}>\tan \theta_{t}$, whereas in the part $\left(a_{1}\right)$ the movement (represented by the broken ines) was westward, since $v_{x} / v_{y} \leqslant \tan \theta_{t}$.

Duration of the Airalow Vallevs in the Meridional Scan Data

Vertical growth and east-west drift of the plasma bubble, as depicted in Figure 1, would cause propagation of airglow depletion valleys in the meridional scan photometer data. We will consider first the duration for which ap airglow valley produced by a given plasma bubble that develops in the same meridional plane as that of the airglow measurement would be tracked in the scanning data (this meridian is indicated by the arrows in Figure 1). If the bubble axis is vertically upward in the equatorial plane, its projection over the low latitude ionosphere will be strictly aligned along the magnetic meridian and, therefore, the maximum duration ( $\tau$ ) for which this could be tracked in the meridional scan photometer would be $\tau=w / v_{x}$, where $w$ is the east-west dimension of the plasma bubble. For a typical value of $w=150 \mathrm{~km}$ and $v_{x}=100 \mathrm{~m} \mathrm{~s}^{-1}, \tau=1500 \mathrm{sec}$. In the long series of meridional scan data now available over Cachoeira Paulista, we have come across widely varying values for $\tau$. The events shown in Figure 2(a) have durations (of the order of 30-35 minutes) compatible with wand $v_{x}$ mentioned above. Events having smaller duration than these could possibly, not necessarily correctly, be explained by smaller $w$ and/or higher $v_{x}$. However, there are frequent cases of large $\tau$ 's that cannot simply be explained by reasonable values of $w$ and $v_{x}$. For example, in the case of the event shown in the part (b) of the Figure 2 that has $T \cong 75$ min the bubble dimension should be $-450 \mathrm{~km}$ if we assume a typical eastward velocity of $100 \mathrm{~m} \mathrm{~s}^{-1}$. There are other examples when simultaneous eastward velocities were also measured. The east-west bubble dimension for many such cases when calculated as $\tau=W / v_{x}$ also come out to be high ( $400 \mathrm{~km}$ or more) (Nakamura et al., 1984, present a typical example of 
such a "long" duration event). Such large east-west dimension for an individual bubble seems to be uracceptable on the basis of sateilite and radar measurements of the bubble cross section (Tsunoda, 1981; Tsunoda et al., 1982; McClure et al., 1977). This difficulty can be overcome if we include the tilt angle $\theta_{t}$ in the determination of the $\tau$. Based on straightforward geometrical considerations from the Figure 1 , we can show that $\tau$ is in fact given by

$$
\tau\left(\text { for } \theta_{t} \lesseqgtr \tan ^{-1}\left(v_{x} / v_{y}\right)\right)=\frac{w}{v_{x}}\left[1 \pm \frac{\tan \theta_{t}}{\left(\frac{v_{x}}{v_{y}}-\tan \theta_{t}\right)}\right]
$$

(t and - signs correspond to the $<$ and $>$ signs, respectively). A plot of the $\tau$, normalized to $w / v_{x}$, against $v_{x} / v_{y}$ is presented in Figure $3(a)$ for different values of the tilt angle, namely, for $\tau_{t}=5^{\circ}$ up to $\theta_{t}=45^{\circ}$. The solid curves represent $\tau /\left(w / v_{x}\right)$ for $\theta_{t} \leq \tan ^{-1}\left(v_{x} / v_{y}\right)$ and the dashed cruves shown, for clarity of the figure, only for $\theta_{t}$ values of $45^{\circ}$ and $5^{\circ}$, represent cases of $\theta_{t}>\tan ^{-1}\left(v_{x} / v_{y}\right)$. When $\theta_{t}=\tan ^{-1}\left(v_{x} / v_{y}\right)+$ becomes infinite, and the plasma bubble projection over low latitude, namely that of the "head" of the bubble, would remain always in the meridional scanning plane and could be tracked until the bubble rises to an altitude over the equator that is traced to a latitude outside the scanning range. On either side of the infinity $\tau$ decreases steadily, towards $\tau=w / v_{x}$ for higher $v_{x} / v_{y}$ values and towards $\tau=2 \mathrm{~W} / \mathrm{v}_{\mathrm{x}}$ for lower values of $v_{x} / v_{y}$, a behaviour clearly noticeable in the case of the curves shown for $\tau_{t}=5^{\circ}$. For $\theta_{t}<\tan ^{-1}\left(v_{x} / v_{y}\right)$ the duration decreases due to the bubble "head" moving outside the scanning plane to eastward (as. shown in Figure 1b), while for $\theta>\tan ^{-1}\left(v_{x} / v_{y}\right)$ the decrease in the duration is due to the bubble "head" moving to westward of the station (as shown in Figure 1a). Thus, from a knowledge of the velocities and east-west dimension of a bubble that could be obtained from the meridional and east-west scanning measurements over low latitude, it seems to be possible to estimate the tilt angle of the plasma bubble in the 
plane. For example, we have estimated with the help of figure 3 (a) that the event presented by Nakanura et al., (1984) in their Figure 1 could have been produced by a plasma bubble having its axis tilted westward by $\sim 20^{\circ}$ in the equatorial plane.

-Figure 2 .

Figure 3 .

For scanning measurements on longitudes westward of the bubble generation (assuming that the horizontal drift of the plasma bubble is always eastward), the detection of the airglow valleys would be restricted to unique combination of $\theta_{t}, v_{x}$ and $v_{y}$. For example, when $\theta_{t}>\tan ^{-1}\left(v_{x} / v_{y}\right)$ and $v_{x} / v_{y} \leqq 1$ (see Figure 1a) airglow valleys could be observed in the meridional scan measurements on longitude westward of that of the bubble onset, but they are most likely to go undetected in equatorward diretions within the scanning range. One possible example of the detection of such a behaviour, namely, observation of the valley in the poleward portion of the scanning range, is present in the event shown in Figure $2(b)$. The first event in part (a) of the Figure 2 also presents a possible exemple of this case.

When the bubble generation occurs on or westward of the longitude of the scanning measurements, airglow valleys should, in general, be always detectable in the scanning measurements. However, for some typical values of $\theta_{t}$ (namely, $\theta<\tan ^{-1}\left(v_{x} / v_{y}\right)$ ) when $v_{x} / v_{y} \leq 1$ it is possible that the valley could be seen mainly in the northern portion of the scanning range. The second event in the Figure $2(a)$ could be representative of such a case. 
Bubble Rise Velocitv Determined From Meridional Velocitv of Airqlaw Vallev

The veritical rise velocity of the plasma bubule in the equatorial plane is related to the meridional velocity of the airglow valley over Cachoeira Paulista, the latter being higher by a factor of approximately 2.5 , as shown by Nakamura (1981) from a detailed numerical simulation of this problem based on plasma bubble generation by Rayjeigh-Taylor instability mechanism. The above relationship of the velocities was obtained assuming that the events that showed systematic poleward propagation of the airglow valleys, in fact, represented the growth phase of a plasma bubble event that had its onset on or close to the longitude of the scanning observation. Depending upon the bubble development phase and separation of the longitudes of the bubble-development and scanning measurements, one could expect results that are different and often difficult to interpreted purely as arising due to vertical rise velocity of the plasma bubble in the equatorial ionosphere. Some specific possibilities are considered below.

a) Observations on, or westward of, the meridian of bubble onset

$$
\theta_{t}>\tan ^{-1} v_{x} / v_{y} \text { (bubble head moving westward): If the }
$$
airglow valley propagates to the southern limit (poleward end) of the scanning range within a time less than or equal to $\tau$, (namely, when the bubbles rise rather rapidly), then the velocity relationship (namely, the vertical bubble velocity being approximately 2.5 times less than the meridional airglow depletion velocity) discussed above is valid. If on the other hand this propagation time is more than $\tau$, then for the time interval that exceeds $T$, the photometer scanning. will not be passing through the "head" of the bubble, but, instead, will include regions of relatively smaller depletion along the bubble axis, thereby causing a discontinuity in the displacement with time of the airglow valleys in the scanning data. This effect could easily be visualized with the help of Figure la. After the 
discontinuity occurs, the valley will be weaker and might be propagating with relatively different velocities, and as such this part of the data will not yield reliable results for the bubble rise velocity as will be shown presentiy.

$$
\text { For } \theta_{t}<\tan ^{-1} v_{x} / v_{y} \text { (bubble head moving eastward), }
$$
scanning observation on meridian westward of that of the bubble onset will not detect any effect.

b) Observation eastward of the meridian of the bubble onset

This corresponds to relatively later phases of a bubble life time and the photometer might be scanning initially through mostly weaker depletion regions. When $\theta_{t} \geqq \tan ^{-1}\left(v_{x} / v_{y}\right)$ the velocity measured as meridional would, in fact, always be an apparent velocity produced by the eastward propagation of the slant bubble axis (see Figure $1 a)$. The vertical apparent velocity $\left(v_{y}^{\prime}\right)$ deduced from this will be related to the eastward velocity by $v_{y}^{\prime}=v_{x} / \tan \theta_{t}$. Plots of $v_{y}^{\prime}$ against $v_{x}$, normalized to $v_{y}$, are presented in part (b) of.Figure 3 for different values of $\theta_{t}$ (for small $\theta_{t}, v_{y}^{\prime}$ could become very high even for small eastward velocity of the airglow patches). This situation, though possible to occur, does not seem to be present in the scanning signatures that we have analysed so far, for the following reasons: The photometer, during its scan in the northern part of the scanning range, should be seeing depletion corresponding to regions closer to the "foot" of the plasma bubble and, therefore, should detect weaker airglow valleys than from the southern part of the scan where it should detect airglow depletion corresponding to the part of the bubble relatively closer to the head of the bubble. Therefore the depth of a valley might increase from north towards south in the scanning range. Results of statistical analysis of a large number of events by Nakamura (1981) showed that the amplitude of the valley varied in exactly opposite sense within the scanning range. 
When $\theta_{t}<\tan ^{-1}\left(v_{x} / v_{y}\right)$ (see Figure 1b) the photometer scan would first intercept relatively weaker depletion regions corresponding to the part of the bubble axis closer to the "foot" of the bubble. However, with passage of time deeper depletion or valley corresponding to regions closer to the bubble "head" would be encountered towards the southern part of the scanning range. The southward propagation of the airglow valley from then -onward will permit valid determination of the vertical bubble rise velocity in the equatorial ionosphere.

Figure 3.

Conclusions

We have considered here different aspects of plasma bubble dynamics in the equatorial ionosphere that leave characteristic signatures in a meridional scanning photometer operated over low latitude. For the bubble axis orientation in the equatorial plane and their vertical and horizontal motions we have considered idealized situations, but based on available vhf radar and satellite observational results. If there would be significant variations in the tilt angle of individual bubole during its life time, this could certainly complicate our interpretation of the scanning data. The most important conclusions from the presents analysis are the following. Rise velocities of the plasma bubble in the equatorial ionosphere could be determined from meridional velocities of the airglow depletion valleys measured by scanning photometers over low latitude when such measurements corresponds to development phase of a bubble event. Such estimations of the rise velocities are easily possible when the bubble onset occurs on or near the magnetic meridian of the scanning measurements. The duration for which an airglow depletion valley is observed in the meridional scanning plane could vary significantly depending upon the rise velocity, eastward drift and tijt angle of the plasma bubble. Most of the 
velocity determination based on the systematic southward displacement of the airglow valley we have carried out so far (Sobral et al., 1980a, 1980b, 1981; Nakamura et al., 1984; Sahai et a1., 1983) seem to conform to these conditions. Since the east-west velocities of airglow valleys obtained from the east-west scan photometer is directly related to the plasma bubble zonal velocities in the equatorial plane and hence their interpretation is rather straightforward, we have not discussed.them here in detail. However, it is worthwhile to point out that since the magnetic flux tube a.lignment characteristics of plasma would permit relating the plasma bubble zonal velocities at the equatorial apex height of the magnetic field line to that measured at the "foot" of the field line over low latitude, simultaneous scanning measurements of East-West velocities of airglow valleys at latitudinally separated stations could enable determination of F-region bulk plasma veloçity. shears in the equatorial ionosphere (Tsunoda et al., 1981; Kudeki et al., 1981, Abdu et al., 1985).

Acknowledgements

This work was partially supported by the "Fundo Nacio nal de Desenvolvimento Cientifico e Tecnologico" under contract FINEP-130CT.

\section{References}

Aarons, J., MUlLem, J.P., Whitney, H.e. \& MACKenzie, e.M. - 1980 The dynamics of equatorial irregularity patch formation, motion and decay, J. Geophys. Res,, 폰 $139-149$.

ABDU, M.A., KANTOR, I.J., BATISTA, I.S. \& PAULA, E.R. - 1984 - Eastwest plasma bubble irregularity motion determined from spaced VHF polarimeters: implications on velocity shear in the zonal F-region bulk plasma motion. Radio Sci., 20, 111:122, 1985. 
ANDERȘON, D.N. \& HAERENDEl, G. - 1979 - The motion of depleted plasmia regions in the equatorial ionosphere. J. Geophys. Res., 84: $4251-4256$.

BALSLEY, B.B., HAERENDEL, G. GREENWALD, R.A. - 1972 - Equatorial spread $F$ : recent observations and a new interpretation. J.Geophys. Res.; 77: 5625-5628.

DYSON, P.L. \& BENSON, R.F. - 1978 - TOPSide sounder observations of equatorial bubbles. Geophys, Res, Lett., $\underline{\underline{5}}:$ 795-798.

HAERENDEL, G. - 1973 - Theory of equatorial spread F. Preprint, Max-Planck Institut, Garching, West Germany.

KUDEKI, E., FEJER, B.G., FARLEY, D.T. \& JERKIC, H.M. - 1981 Interferometer studies of equatorial F-region irregularities and drifts. Geophys. Res. Lett., 8: $377-380$.

MCCLURE, J.P., HANSON, W.B. \& HOFFMAN, J.F. - 1977 - PTasma bubbles and irregularities in the equatorial ionosphere. J. Geophys. Res., 82: $2650-2656$.

MENDILLO, M. and BAUMGARDNER, J. - 1982 - Airglow characteristics of equatorial plasma depletions. J. Geophys. Res., 87: 7641-7652.

NAKAMURA, Y. - 1981 - Irregularidades ionosfëricas em baixas latitudes no setor Americano - PhD Thesis, Instituto de Pesquisas Espaciais, Brazil.

NAKAMURA, Y., SOBRAL, J.H.A. \& ABDU, M.A. - 1984 - A simulation of equatorial plasma bubble signatures on the 016300 \& nightglow meridional profile over Brazilian low latitude. Revista Brasilei ra de Geofisica, in press. 
OSSAKOW, S.L., ZALESAK, S.T., MCOONALD, B.E. \& CHATURVEDI, P.K. - 1979 Nonlinear equatorial spread $F$ : dependence on altitude of $F$ peak and bottomside background electron density gradient scale length. J. Geophys, Res., 84: 17-29.

SAHAI, Y., BITTENCOURT, J.A., TEIXEIRA, N.R. \& TAKAHASHI, H. - 1983 Observations of large scale $F$ region irregularities using airgiow emissions at $7774 \AA$ and $6300 \AA$. Annals Geophys., 1: 271-276.

SOBRAL, J.H.A., ABDU, M.A. BATISTA, I.S. - 1980a - Airglow studies on the ionosphere dynamics over low Latitude in Brazil. Ann. Geophys, , 36: $199+214$

SOBRAL, J.H.A., ABDU, M.A., ZAMLUTTI, C.J. \& BATISTA, I.S. - 1980b Association between plasma bubble irregularities and airglow disturbances over Brazilian low latjtudes. Geophys. Res. Lett., 7: $980-982$.

SOBRAL, J.H.A., ABDU, M.A., BATISTA, I.S. \& ZAMLUTTI, C.J. - 1981 Wave disturbance on the low latitude ionosphere and equatorial ionospheric plasma depletions. J. Geophys, Res., 86: 1374-1378.

TSUNODA, R.T. - 1980 - Magnetic fieldwaligned characteristics of plasma bubbles, in the nighttime equatorial ionosphere. J. Atmos. Terr. Phys., 42: 743-752

TSUNODA, R.T. - 1981 - Time evolution and dynamics of equatorial backscatter plumes, 1. Growth phase. J. Geophys. Res., 86: 139-149.

TSUNODA, R.T. \& WHIT, B.R. - 1981. On the generation and growth of equatorial backscatter plumes: 1 . Wave structure in the bottomside F-1ayer. J. Geophys. Res., 86: 3610-3616. 
TSUNODA, R.T., LIVINGSTON, R.C. MCCLURE, J.P. \& HANSON, W.B. - 1982 Equatorial plasma bubble: vertically-elongated wedges from the bottomside F-layer. J, Geophys. Res., 87: 9171-9180.

WEBER, E.J., BUCHAd, J. \& MOORE, J.G. - 1980 - Airbone studies of equatorial F-layer ionospheric irregularities. J. Geophys. Res., 85: $4631-4641$.

WEBER. E.J., BUCHAU, J., EATHER, R.H. \& MENDES, S.B. - 1978 - North-south aligned equatorial airglow depletions. J. Geophys. Res., 83: $712-716:$

WOODMAN, R.F. and LA HOZ, C. - 1976 - Radar observations of F-region equatorial irregularities. 3. Geophys. Res., 81: 5447-5466. 
ON THE LOW LATITUDE SCANNING PHOTOMETER SIGNATURES

OF EQUATORIAL IONOSPHERE PLASMA BUBBLES

M. A. ABDU, 3. H. A. SOBRAL, AND Y. NAKAMURA

NOMERO DE FIGURAS: 3 


\section{LEGENOAS DAS FIGURAS}

Figure 1. $\left(a_{1}\right)$ Plasma bubble orientations in the equatorial plane (represented by the bubble axis of simmetry in this plane) shown for different times, at intervals of 10 minutes, starting from the onset $(t=0)$, the separation of the lines being representative of an eastward velocity $v_{x}=100 \mathrm{~m} \mathrm{~s}^{-2}$. The horizontal scale is marked at $100 \mathrm{~km}$. The bubble axes are shown with a tilt angle, $\theta_{t}$, of $45^{\circ}$ assumed fixed with time. The solid lines represent bubble axes orientations when the vertical rise velocity $v_{y}$ is equal to the eastward velocity $v_{x}$ of the bubble. The extensions of these lines by dashes represented the case of $v_{y}=2 v_{x} \cdot$

( $\left.a_{2}\right)$ Projection along the magnetic field lines, onto the low latitude ionosphere at $250 \mathrm{~km}$, of the bubble axis. The latitude of the scanning photometer location is marked by the horizontal line at $1400 \mathrm{~km}$ from the equator. The meridional scanning range extends from $600 \mathrm{~km}$ to $2200 \mathrm{~km}$ from the equator shown along the $y$ axis.

$\left(b_{2}\right)$ Same as $\left(a_{3}\right)$ but for $\theta_{t}=20^{\circ}$.

$\left(b_{2}\right)$ Projection of the bubble axes as in $\left(a_{2}\right)$.

Figure 2: (a) An example of a meridional scan 6300 a arglow intensity profiles showing an airglow valley predominantly on the sourthern portion (upper part) and another predominantly on the northern portion (lower part) of the scanning range. They correspond to the circumstances described in the text. The intensity scales are arbitrary. These two events are representative of medium duration events for which experimentally observed average values of $w$ and $v_{x}$ would seem to apply. Local times are marked on the intensity profile as well as on the corresponding base line. 
(b) A long duration event that al so shown presence of an airglow valley predominantly on the sourthern portion of the scanning range. The right end of the meridional profiles (marked $75^{\circ} \mathrm{N}$ ) is the northern limit and the left end (marked $75^{\circ} \mathrm{S}$ ) is the southern limit of the scannings.

Figure 3. (a) Curves of $\tau /\left(w / v_{x}\right)$ versus $v_{x} / v_{y}$ as per the Equation 1 in the text, plotted for $\theta_{t}=5^{\circ}$ up to $45^{\circ}$ in steps of $5^{\circ}$. The solid curves represents the case of + sign and the dotted curves represent the case of - sign (corresponding to the cases of $\theta_{t}<\tan ^{-1}\left(v_{x} / v_{y}\right)$ and $\theta_{t}>\tan ^{-1}\left(v_{x} / v_{y}\right)$, respectiveiy) of the Equation 1.

(b) Plots of $v_{y}^{\prime} / v_{x}$ versus $v_{x} / v_{y}$ for different values of. $\theta_{t}$ according to the expression $x_{y}^{\prime}=v_{x} / \tan \theta_{t}$ discussed in the text. 


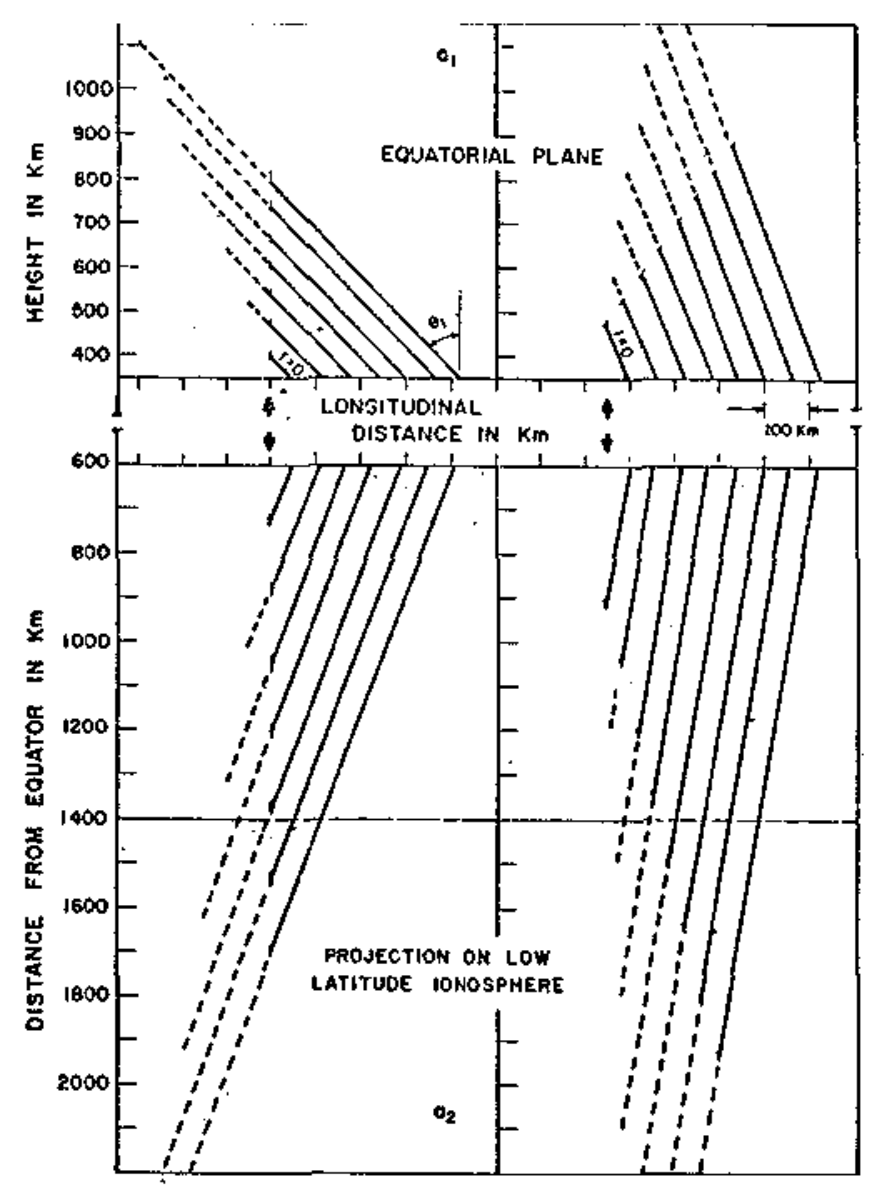

Fig. 1 


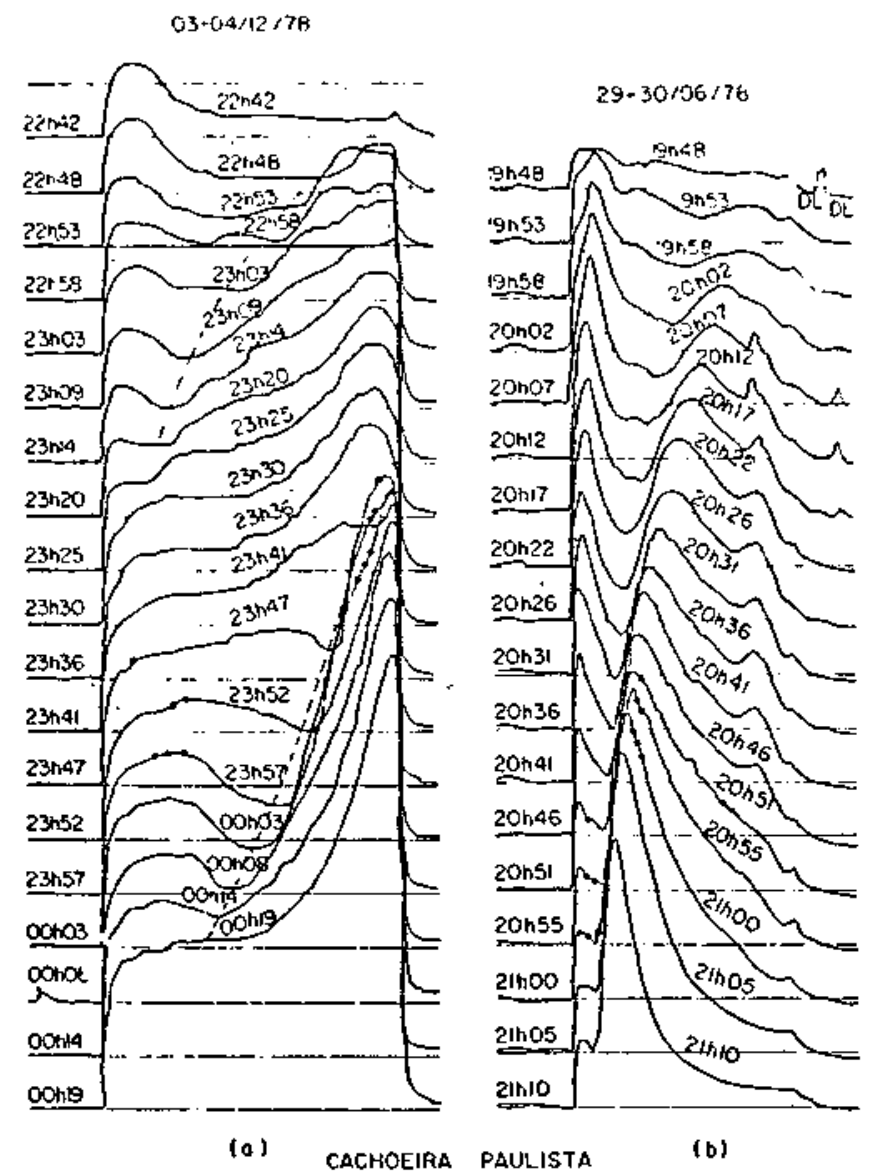

Fig. 2 

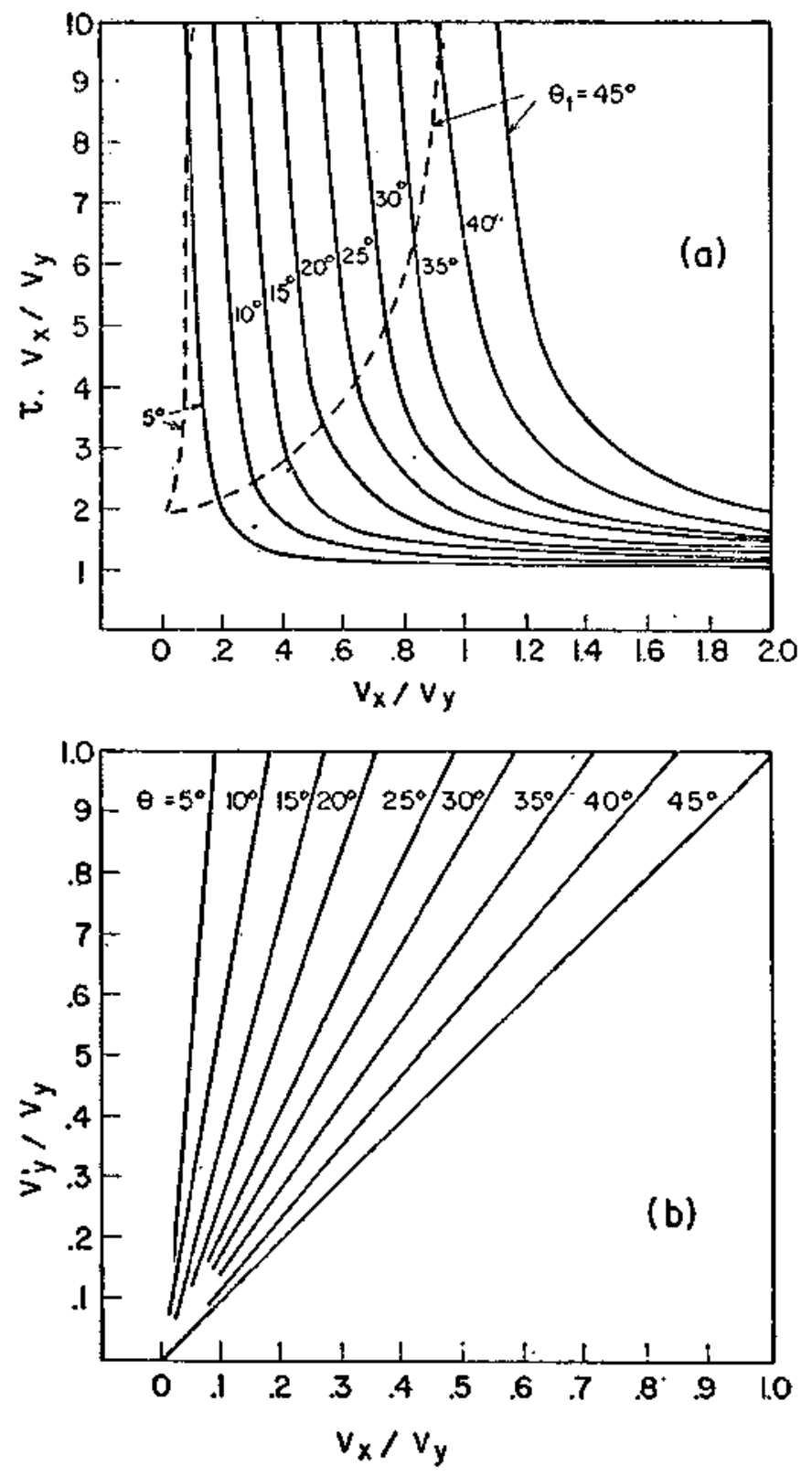

Fig. 3 